\title{
QUANTIFICAÇÃO DA BIOMASSA E DOS TEORES DE CARBONO DE PTERIDÓFITAS ARBORESCENTES EM FLORESTA OMBRÓFILA MISTA
}

\author{
Juliana Klostermann Ziemmer ${ }^{1 *}$, Alexandre Behling ${ }^{2}$, Ana Paula Dalla Corte ${ }^{3}$ \\ 1* Universidade Federal do Paraná, Curitiba, Paraná, Brasil, juliana ziemmer@yahoo.br \\ ${ }^{2}$ Universidade Federal do Paraná, Departamento de Ciências Florestais, Curitiba, Paraná, Brasil, \\ alexandre.behling@yahoo.com.br
}

${ }^{3}$ Universidade Federal do Paraná, Departamento de Ciências Florestais, Curitiba, Paraná, Brasil, anapaulacorte@gmail.com

\section{Resumo}

O presente trabalho teve como objetivo quantificar a biomassa, o estoque e os teores de carbono em duas espécies de pteridófitas arborescentes: Dicksonia sellowiana e Cyathea corcovadensis, ambas de ocorrência natural na formação Floresta Ombrófila Mista (FOM). Este estudo foi desenvolvido na Estação Experimental da Universidade Federal do Paraná, localizada no município de Rio Negro, PR, a qual detém uma área de 7,5 ha com regeneração natural de xaxins. Foram instaladas 20 parcelas de $50 \mathrm{~m}^{2}$ para execução de um inventário florestal e, com base nos dados do inventário, foram selecionados 20 indivíduos de cada espécie para mensuração da biomassa, com finalidade de construir equações. Foram testados seis modelos, os quais foram ajustados utilizando o método dos mínimos quadrados ordinários, em que a seleção das melhores equações foi feita tomando como base as estatísticas do coeficiente de determinação ajustado ( $\left.R^{2} a j\right)$, erro padrão da estimativa (Syx\%) e análise gráfica da distribuição dos resíduos. A partir dos dados de altura e diâmetro da base foi estimada a biomassa seca dos componentes de cada indivíduo por meio das equações obtidas e, posteriormente, extrapolou-se os valores de biomassa para a unidade hectare. Ainda, foram determinados os teores de carbono para os componentes da biomassa (fuste, folhas e total) por meio de um analisador de carbono em sólidos (Leco C-144). O estoque de carbono foi obtido por meio da multiplicação do estoque da biomassa de cada componente pelo respectivo teor médio de carbono. Para o estoque total de carbono, foi utilizado o teor médio de carbono ponderado. Para Dicksonia sellowiana o estoque médio de biomassa do componente fuste foi de $29,43 \mathrm{t}^{-h^{-1}}$, para folhas igual a 4,34 t.ha-1 e para a biomassa total equivalente a 32,24 tha $\mathrm{t}^{-1}$. Cyathea corcovadensis obteve média de 2,75 tha ${ }^{-1}$ para fuste, 0,47 t.ha $^{-1}$ para folhas e 3,53 t.ha-1 para a biomassa total. A média dos teores de carbono para o componente fuste foi de $40,53 \%$; a folhagem obteve média de $38,64 \%$. Considerando todos os componentes, o valor médio ponderado dos teores de carbono foi de $40,28 \%$. O estoque médio total de carbono foi de 13,03 t.ha $^{-1}$, o que evidencia a importância dessas espécies no sequestro e fixação de carbono e, consequentemente, à minimização do aquecimento global.

Palavras-chave: Xaxim; Fixação de carbono; Mudanças climáticas.

\begin{abstract}
Biomass quantification and carbon content of arborescent pteridophytes In Ombrophilous Mixed Forest. This study aimed to quantify the biomass stocks and carbon contents in two species of arborescent ferns: Dicksonia sellowiana and Cyathea corcovadensis, both naturally occurring in the formation Araucaria Forest (FOM). This study was conducted at the Experimental Station of the Federal University of Paraná, located in the municipality of Rio Negro, PR, which has an area of 7.5 ha with natural regeneration of xaxins. 20 plots of $50 \mathrm{~m}^{2}$ for execution of a forest inventory were installed. Based on inventory data, were selected 20 individuals of each species to measure biomass, aiming to build biomass equations. Six models were tested, which were adjusted using the method of ordinary least squares, selecting the best equation was made based on the statistics of the adjusted coefficient of determination ( $\left.R^{2} a j\right)$, standard error of estimate (Syx\%) and graphical analysis of distribution of residuals. From the data of height and base diameter, was estimated dry biomass of the components of each individual from the obtained equations and then extrapolated the values of biomass for hectare unit. Also, was determined the levels of carbon to biomass components (caudex, leaves and total) using carbon analyzer in solid (Leco C-144). The carbon stock was obtained by multiplying the biomass stock of each component by its average carbon content. For total carbon stock the weighted average carbon content was used. Dicksonia sellowiana to the average biomass stock caudex component was 29.43 t.ha $^{-1}$ for leaves and 4.34 t.ha $^{-1}$ for total
\end{abstract}


biomass 32.24 t.ha $^{-1}$. Cyathea corcovadensis had an average of 2.75 t.ha $^{-1}$ for caudex, 12.47 t.ha-1 for the leaves and 3,53 t.ha $^{-1}$ for total biomass. The average of the carbon component to the caudex was $40.53 \%$; the foliage had an average of $38.64 \%$. Considering all the components, the weighted average carbon content was $40.28 \%$. The average total carbon stock was 13.03 t.ha ${ }^{-1}$, which highlights the importance of these species in the fixation and sequestration and consequently to minimize global warming.

Keywords: Xaxim; Carbon sequestration; Climate change.

\section{INTRODUÇÃO}

A ação do homem e a exploração descontrolada dos recursos naturais têm contribuído para o aumento da concentração de gases do efeito estufa (GEE), com profundas mudanças nos padrões climáticos do planeta. Atualmente, seis gases são considerados como causadores do efeito estufa: dióxido de carbono $\left(\mathrm{CO}_{2}\right)$, metano $\left(\mathrm{CH}_{4}\right)$, óxido nitroso $\left(\mathrm{N}_{2} \mathrm{O}\right)$, clorofluorcarbonetos (CFCs), hidrofluorcarbonetos (HFCs) e hexafluoreto de enxofre $\left(\mathrm{SF}_{6}\right)$. Segundo o IPCC (2007), a queima de combustíveis fósseis e as mudanças no uso do solo são apontados como as principais contribuições humanas para a intensificação das mudanças do clima.

Uma das estratégias para diminuir a concentração desses gases é incorporá-los na biomassa vegetal (CAVALLET; PAULA, 2007). Dessa forma, as florestas assumem papel importante na mitigação do aquecimento global, pois absorvem $\mathrm{CO}_{2}$ da atmosfera por meio da fotossíntese e armazenando grandes quantidades de carbono na biomassa. De acordo com Watzlawick (2004), as florestas são importantes para o equilíbrio do balanço global de gás carbônico, pois os diferentes tipos de florestas armazenam diferentes quantidades de carbono em função dos estágios de sucessão, da idade, do regime de manejo e da composição de espécies.

A Floresta Ombrófila Mista, também denominada como mata-de-araucária ou pinheiral, originalmente cobria cerca de $200 \mathrm{mil} \mathrm{km}^{2}$ em todo Brasil (IBGE, 1993), abrangendo principalmente os estados do Paraná, Santa Catarina e Rio Grande do Sul. Atualmente, encontra-se com escassos remanescentes de vegetação, não chegando a perfazer $5 \%$ de sua área original. Sua composição florística é caracterizada pela presença de Araucaria angustifólia Kuntze e de outros gêneros primitivos, como Drymis e Podocarpus (IBGE, 2012).

O conhecimento da capacidade de absorção de carbono na biomassa florestal em diferentes tipologias fornece informações para o direcionamento das decisões que possam contribuir para a conservação das florestas. Por esse motivo, é crescente o interesse pelos estudos de biomassa e carbono em florestas (SILVEIRA, 2008). De acordo com Sanquetta (2002), um dos aspectos mais relevantes nos estudos de fixação de carbono em florestas é a variável biomassa, a qual precisa ser determinada e estimada de forma confiável para a consistência na quantificação do carbono fixado nos ecossistemas florestais.

Em geral, estudos sobre fixação de carbono estão direcionados para espécies florestais arbóreas, ocorrendo que alguns grupos de plantas são pouco considerados, como é o das pteridófitas, as quais compõem um importante grupo de organismos da flora. As pteridófitas apresentam aspectos ecológicos bem diversificados, incluindo plantas terrícolas, epífitas, rupícolas, aquáticas e escandentes e variando desde plantas minúsculas até aquelas com $20 \mathrm{~m}$ de altura, como é os xaxins (LEHN et al., 2002), em que as famílias Dicksoniaceae e Cyatheaceae apresentam o maior número de espécies (PEREIRA, 2003).

Com base no exposto, o presente estudo teve como objetivo quantificar a biomassa, o estoque e os teores de carbono de duas espécies de pteridófitas arborescentes: Dicksonia sellowiana Hook. (Dicksoniaceae) e Cyathea corcovadensis (Raddi) Domin (Cyatheaceae), ambas de ocorrência natural na formação Floresta Ombrófila Mista no estado do Paraná

\section{MATERIAL E MÉTODOS}

\section{Descrição da área de estudo}

O presente estudo foi realizado na Estação Experimental de Rio Negro da Universidade Federal do Paraná, estado do Paraná, localizada no município de Rio Negro, PR, entre as coordenadas $26^{\circ} 06$ Sul e $49^{\circ} 47$ Oeste, a uma altitude média de $780 \mathrm{~m}$ (Figura 1). A Estação Experimental possui uma área 
de 127,52 ha com florestas naturais, reflorestamentos, campos, pastagens e outros usos do solo (SANTOS, 2006). Em 1967, um povoamento de Araucaria angustifolia Kuntze foi implantado em uma área de 1,4 ha, apresentando regeneração natural de xaxins em seu sub-bosque.
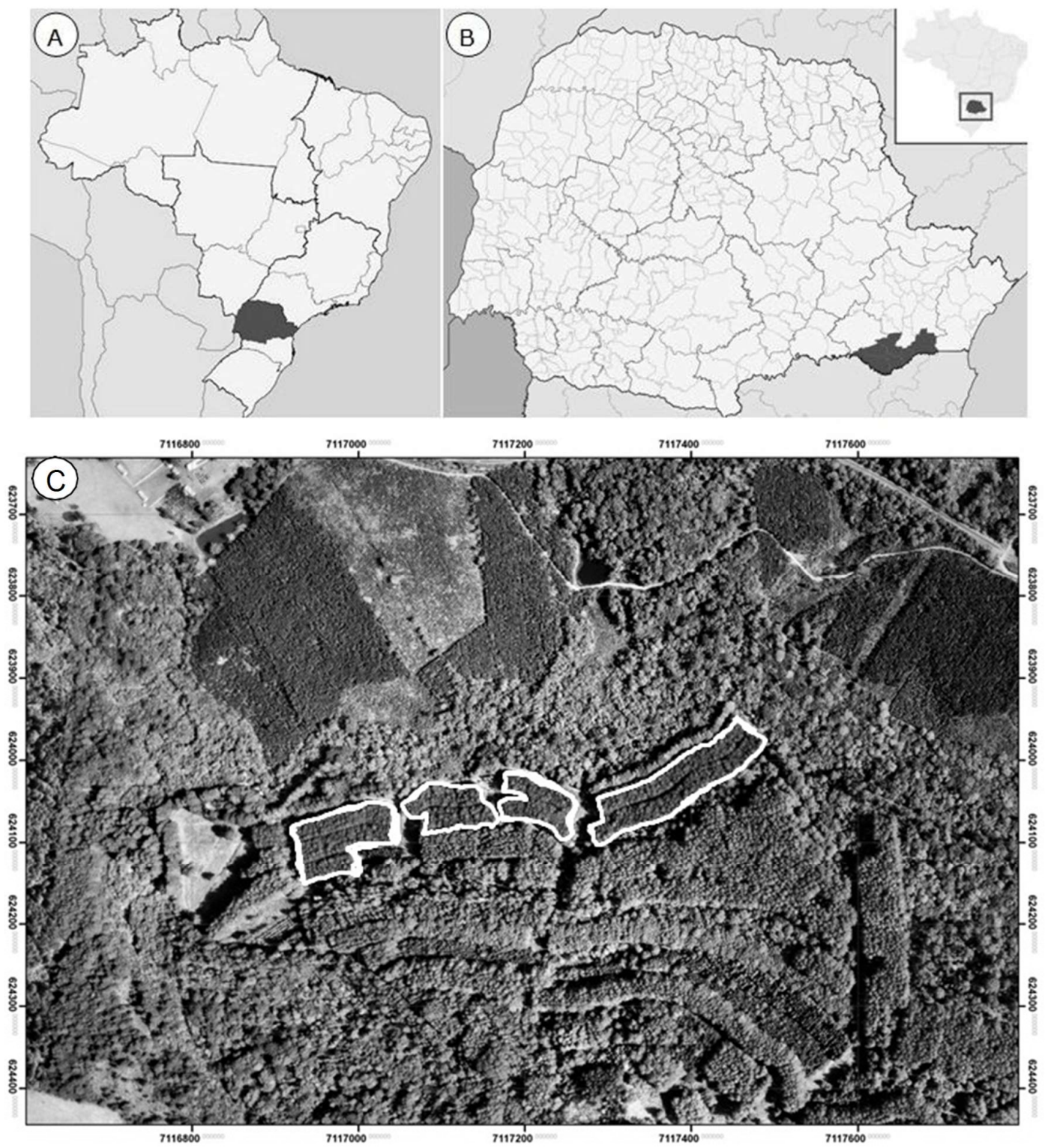

Figura 1. Localização da área de estudo. (A) estado do Paraná; (B) município de Rio Negro - PR; (C), vista aérea do fragmento.

A tipologia vegetal da área corresponde à formação Floresta Ombrófila Mista. Conforme a classificação de Köppen, o clima da região é Subtropical Úmido Mesotérmico (Cfb), sem estação seca severa, com verões frescos e invernos com geadas frequentes. Os solos da estação se dividem em dois grandes grupos, os Latossolos arenosos e os solos hidromórficos (DOBNER JUNIOR et al., 2013).

\section{Descrição das espécies}

A espécie Dicksonia sellowiana, popularmente conhecida como xaxim-verdadeiro ou xaximbugio, é uma pteridófita arborescente que possui caule geralmente ereto, com densos tricomas e raízes adventícias que ocorrem da base até próximo do ápice do fuste até $10 \mathrm{~m}$ de altura e com folhas 
bipinadas de 1 a 5 m (MANTOVANI, 2004). Ocorre naturalmente desde a Guatemala até a Venezuela e o Equador (SEHNEM, 1878), ao passo que no Brasil, ocorre nos estados de Minas Gerais, São Paulo, Rio de Janeiro, Paraná, Santa Catarina e Rio Grande do Sul (MANTOVANI, 2004). Essa espécie está incluída na lista oficial da flora ameaçadas de extinção pela Portaria nº 06 do IBAMA.

A espécie Cyathea corcovadensis, conhecida comumente como xaxim-de-espinho, apresenta fuste com até $5 \mathrm{~m}$ de altura e folhas bipinadas que podem atingir até $3 \mathrm{~m}$ de comprimento, com pecíolo resistente e muitos espinhos (NEUMANN, 2010). No Brasil, ocorre nos estados de Pernambuco, Bahia, Alagoas, Minas Gerais, Espírito Santo, Rio de Janeiro, São Paulo, Paraná, Santa Catarina e Rio Grande do Sul (HIRAI; PRADO, 2014). A espécie está na lista da flora ameaçada de extinção do estado Rio Grande do Sul, na categoria em perigo (SEMA, 2007).

\section{Inventário florestal}

Para a realização do inventário florestal, foram instaladas 20 parcelas com área de $50 \mathrm{~m}^{2} \mathrm{de}$ forma aleatória, totalizando uma área amostral de $1.000 \mathrm{~m}^{2}$. Um receptor de GPS, Modelo GPSmap 60CSx Garmim, foi utilizado para o registro da localização das parcelas. Em cada parcela, foram mensuradas as seguintes variáveis dendrométricas: altura total, altura comercial, DAP (diâmetro à altura do peito) e diâmetro ao longo do fuste (base, meio e topo).

\section{Ajuste de equações para estimativa da biomassa}

Em virtude das restrições de ordem legal e operacional, a estimativa da biomassa foi realizada pelo método não destrutivo. Com base nos dados obtidos no inventário florestal, foram selecionados 40 indivíduos, sendo 20 de cada espécie. Os indivíduos de Dicksonia sellowiana foram selecionados proporcionalmente em relação às classes de altura (Figura 2), pois não foram todos os exemplares que apresentaram DAP mensurável, elegendo dois indivíduos por classe, com exceção da classe de maior frequência, na qual foram selecionados três.

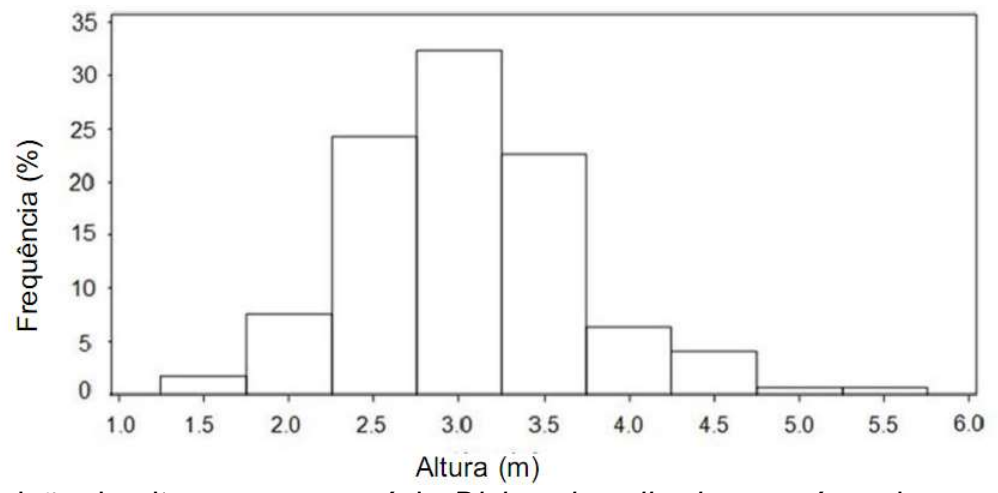

Figura 2. Distribuição da altura para a espécie Dicksonia sellowianaem área de ocorrência natural na Floresta Ombrófila Mista.

Para a Cyathea corcovadensis, foram observados somente 20 indivíduos no inventário florestal, cuja altura variou entre $1,77 \mathrm{~m}$ a 4,48 $\mathrm{m}$, os quais foram selecionados para a quantificação da biomassa. A determinação da biomassa do fuste foi obtida multiplicando-se o volume do fuste por sua densidade básica média. Para determinação do volume, foram tomados diâmetros em três posições (base, meio e topo) e determinado por meio do método de Smalian descrito por Sanquetta (2002). Para a obtenção da densidade básica, foi utilizado o procedimento de imersão em água, descrito pela norma NBR 11941/2003 (ABNT, 2003). Em consequência da impossibilidade de cortar os indivíduos, foram retiradas amostras do fuste nas posições base e topo com auxílio de um trado. Para cada indivíduo considerou-se o valor médio da densidade básica obtido nas duas posições.

Para a determinação da biomassa das folhas, foi procedida a contagem do número de folhas de cada indivíduo e, em seguida, coletado seis folhas em diferentes posições da copa (base, meio e ápice) e em direções opostas. O peso verde das folhas foi obtido com balança eletrônica com capacidade de $20 \mathrm{~kg}$. Posteriormente, as amostras foram levadas à estufa com renovação de $\operatorname{ar}$ a $70^{\circ} \mathrm{C}$ para secagem até peso constante. Com base nos valores de peso verde e peso seco, foi possível obter 
estimativas da biomassa seca das folhas e, com isso, um peso médio de cada folha. A obtenção da biomassa das folhas por indivíduo foi obtida multiplicando-se o peso médio da folha pelo número de folhas contadas.

Para o ajuste dos modelos de estoque individual de biomassa, a biomassa seca $(\mathrm{kg})$ individual dos componentes foi utilizada como variável dependente e o diâmetro da base $(\mathrm{cm})$ e a altura total $(\mathrm{m})$, bem como suas combinações e transformações, como variáveis independentes. $O$ ajuste das equações para estoque de biomassa foi realizado para seis modelos selecionados na literatura, os quais estão listados na Tabela 1.

Tabela 1. Modelos testados para ajuste de equações de biomassa

\begin{tabular}{lc}
\hline & Modelo \\
\hline 1 & $w=a+b\left(d^{2} h\right)+e i$ \\
2 & $w=a+b\left(d^{2}\right)+e i$ \\
3 & $w=a+b(d)+e i$ \\
4 & $\ln (w)=a+b \cdot \ln (d)+c \cdot \ln (h)+e i$ \\
5 & $\ln (w)=a+b \cdot \ln \left(d^{2} h\right)+e i$ \\
6 & $\ln (w)=a+b \cdot \ln (d)+c \cdot \ln (h)+e\left(d^{2} h\right)+e i$ \\
\hline
\end{tabular}

Em que: $w=$ biomassa seca individual $(\mathrm{kg})$ de um dado componente da biomassa; $a, b, c$ e $e=$ coeficientes a serem ajustados; $\ln$ = logaritmo na base neperiana; $e i=$ erro aleatório associado; $d$ = diâmetro da base $(\mathrm{cm})$; e $h$ $=$ altura total $(\mathrm{m})$.

O ajuste das equações foi realizado pelo método dos mínimos quadrados ordinários utilizando o software Microsoft Office Excel 2007. As melhores equações de regressão foram selecionadas a partir dos seguintes critérios estatísticos: maior coeficiente de determinação ajustado ( $\left.R^{2} a j\right)$, menor erro padrão da estimativa (Syx\%) e melhor distribuição gráfica dos resíduos.

Após uma análise de covariância (SCHNEIDER et al., 2009), foi observado que não seria necessário utilizar uma equação individual para cada espécie. Sendo assim, os ajustes foram feitos tomando os 40 pares de dados. Os valores de biomassas obtidos por equações logarítmicas foram corrigidos pelo Índice de Meyer (IM). A partir disso, as estatísticas $\mathrm{R}^{2}$ aj e Syx\% foram recalculadas, permitindo a comparação das equações de natureza aritmética e logarítmica.

\section{Quantificação de biomassa}

A partir dos dados de altura e diâmetro da base, obtidos no inventário florestal, foi estimada a biomassa seca dos compartimentos de cada indivíduo por meio das equações obtidas. A biomassa em t.ha ${ }^{-1}$ foi extrapolada utilizando-se a seguinte equação:

$$
B i=\frac{\sum_{i=1}^{n} b i}{A i}
$$

Em que: $B i=$ biomassa seca de um dado componente ou total, em toneladas; $\sum_{i=1}^{n} b i=$ somatório da biomassa de todos os indivíduos que compunham uma determinada parcela, em toneladas; e $A i$ = área de uma determinada parcela, em hectares.

\section{Quantificação dos teores e estoque de carbono}

Devido à impossibilidade de seccionar os indivíduos, as amostras para análise de carbono do fuste foram retiradas com auxílio do Trado de Pressler, sendo duas amostras da base e duas abaixo do ponto de inversão morfológica. De acordo com Oshiro (2010), a utilização do Trado de Pressler para a coleta de amostras florestais para análise de teores de carbono é uma alternativa não agressiva e que deve ser utilizada em detrimento do sistema de amostragem destrutivo. Para análise do teor de carbono das folhas, foram utilizadas amostras de aproximadamente $200 \mathrm{~g}$ por indivíduo, proveniente das coletas para estimativa da biomassa.

$\mathrm{O}$ material coletado foi seco em estufa de circulação e renovação de ar a $75^{\circ} \mathrm{C}$ até atingir o peso constante. Após esse processo, as amostras foram moídas em moinho Willey, e em seguida foi realizada a determinação dos teores de carbono por meio de um analisador de carbono em sólidos (Leco C-144) no Centro de Excelência em Pesquisas sobre Fixação de Carbono na Biomassa da Universidade Federal do Paraná. 
Os dados de carbono foram submetidos à análise de variância utilizando o modelo para o delineamento inteiramente casualizado. Os fatores de estudo considerados foram: espécie, componente da biomassa (fuste e folhas) e sua interação. Foram testadas as pressuposições da análise de variância, por meio do teste de Bartlett, e assim verificou-se a necessidade de transformação dos teores de carbono para $X^{2}$.

O estoque de carbono foi calculado para os componentes: folhas, fuste e total. O estoque de carbono foi obtido por meio da multiplicação do estoque da biomassa de cada componente (fuste, folhas e total) pelo respectivo teor médio de carbono. Para o estoque total de carbono, foi utilizado o teor médio de carbono ponderado, uma vez que os componentes com mais biomassa devem participar com mais peso na média.

\section{Dióxido de carbono equivalente}

Para a comercialização de créditos de carbono é necessário fazer a conversão do carbono orgânico acumulado na biomassa para um valor que corresponda ao dióxido de carbono $\left(\mathrm{CO}_{2}\right.$ equivalente). A possibilidade de geração dos créditos de carbono por meio da atividade florestal é um mecanismo de interesse de muitos países, tendo aplicação em diversos projetos, como, por exemplo, o mecanismo de desenvolvimento limpo (MDL), a redução de emissões por desmatamento e degradação evitados (REDD e REDD+), a ação nacional apropriada de mitigação (NAMA), os pagamentos por serviços ambientais, as bolsas verdes, entre outros. A conversão de toneladas de carbono por hectare (t.ha) para toneladas de dióxido de carbono por hectare $\left(\mathrm{tCO}_{2}\right.$.ha) foi calculado pela multiplicação do carbono orgânico pelo fator de expansão 3,67.

\section{RESULTADOS E DISCUSSÃO}

\section{Inventário florestal}

Foram mensurados 193 indivíduos nas 20 parcelas instaladas, em que Dicksonia sellowiana apresentou maior densidade de indivíduos por hectare, de 172 árvores.ha- $^{-1}$, em relação à espécie Cyathea corcovadensis, equivalente a 21,05 árvores. ha ${ }^{-1}$. Na Tabela 2 é apresentado um resumo das principais medidas dendrométricas obtidas no inventário.

Tabela 2. Resumo das variáveis dendrométricas obtidas no inventário florestal das espécies Dicksonia sellowiana e Cyathea corcovadensis em fragmento de Floresta Ombrófila Mista

\begin{tabular}{ccccccccccccc}
\hline \multirow{2}{*}{ Espécie } & \multicolumn{3}{c}{ DB $\mathbf{( c m})$} & \multicolumn{3}{c}{ DT $(\mathbf{c m})$} & \multicolumn{3}{c}{ HF $(\mathbf{m})$} & \multicolumn{3}{c}{ HT $(\mathbf{m})$} \\
\cline { 2 - 12 } & Mín & $\overline{\mathbf{x}}$ & Máx & Mín & $\overline{\mathbf{x}}$ & Máx & Mín & $\overline{\mathrm{x}}$ & Máx & Mín & $\overline{\mathbf{x}}$ & Máx \\
\hline D. sellowiana & 11,3 & 28,9 & 49,5 & 10,0 & 21,6 & 41,5 & 0,9 & 1,6 & 3,5 & 1,3 & 3,0 & 5,6 \\
C. corcovadensis & 15,2 & 20,5 & 38,6 & 15,0 & 20,3 & 28,6 & 0,9 & 1,2 & 2,0 & 1,7 & 2,4 & 4,5 \\
\hline
\end{tabular}

Em que: $\mathrm{DB}$ = diâmetro da base; $\mathrm{DT}$ = diâmetro do topo; HF = altura do fuste; $\mathrm{HT}$ = altura total; Mìn = mínimo; $\overline{\mathrm{x}}=$ média; e Máx = máximo.

\section{Densidade básica média}

Na Tabela 3 são apresentadas as estatísticas descritivas da densidade básica média para as duas espécies. A densidade básica média de Dicksonia sellowiana variou entre $125,37 \mathrm{~kg} \cdot \mathrm{m}^{-3}$ a 212,71 $\mathrm{kg} \cdot \mathrm{m}^{-3}$ e média de 169,68 kg.m³. Já para a espécie Cyathea corcovadensis, a variação foi entre 104,09 $\mathrm{kg} \cdot \mathrm{m}^{-3}$ a $204,94 \mathrm{~kg} \cdot \mathrm{m}^{-3}$ e média de $162,70 \mathrm{~kg} \cdot \mathrm{m}^{-3}$.

Tabela 3. Densidade básica média $\left(\mathrm{kg} \cdot \mathrm{m}^{-3}\right)$ das espécies Dicksonia sellowiana e Cyathea corcovadensis em fragmento de Floresta Ombrófila Mista

\begin{tabular}{ccc}
\hline Estatística & Dicksonia sellowiana & Cyathea corcovadensis \\
\hline Média & 169,68 & 162,70 \\
Desvio padrão & 25,39 & 25,91 \\
Mínimo & 125,37 & 104,09 \\
Máximo & 212,71 & 204,94 \\
\hline
\end{tabular}




\section{Quantificação de biomassa}

A biomassa seca total média dos 40 xaxins foi de $16,05 \mathrm{~kg}$, com variação de 2,15 a $57,87 \mathrm{~kg}$ (Tabela 4). Miranda et al. (2012), ao estudarem a biomassa de Euterpe oleracea Mart., encontraram valores médios de $19,06 \mathrm{~kg}$ de biomassa seca total.

Tabela 4. Estatística descritiva da biomassa individual de cada componente de Dicksonia sellowiana e Cyathea corcovadensis em um fragmento de Floresta Ombrófila Mista

\begin{tabular}{cccc}
\hline Estatística & Fuste $\mathbf{( k g )}$ & Folhas $\mathbf{( k g )}$ & Total $\mathbf{( k g )}$ \\
\hline Média & 13,83 & 2,22 & 16,05 \\
Desvio padrão & 11,59 & 1,78 & 13,07 \\
Mínimo & 1,13 & 0,26 & 2,15 \\
Máximo & 51,82 & 7,74 & 57,87 \\
\hline
\end{tabular}

De acordo com Pellizzaro (2009), em formações florestais, as proporções de biomassa da parte aérea de espécies arbóreas apresentam-se sempre em maior quantidade no caule, seguidas de galhos e folhas. Neste estudo, o estoque individual de biomassa seca para a espécie Dicksonia sellowiana se distribuiu nas seguintes proporções: fuste com $85,32 \%$ e folhas com 14,68; ao passo que para Cyathea corcovadensis foi obtida a distribuição de $88,11 \%$ para fuste e de 11,89 para folhas.

Urbano (2007), estudando bracatingas nativas da região metropolitana de Curitiba, encontrou valores para massa seca de $69,82 \%$ para o fuste, $11,51 \%$ para galhos com diâmetro maior que $4 \mathrm{~cm}$, $5,57 \%$ para as folhas e $3,83 \%$ para galhos mortos. Miranda (2008), em um estudo sobre espécies em área de restauração florestal com diferentes idades, encontrou como teor de massa seca, num grupo de espécies, a seguinte ordem: galhos (38,7\%), fuste $(28,8 \%)$, raízes $(20,1 \%)$, folhagens $(7,2 \%)$ e casca $(5,3 \%)$.

$\mathrm{Na}$ Tabela 5 estão apresentadas as estatísticas descritivas da biomassa por hectare para as duas espécies. Dicksonia sellowiana obteve maior média, sendo 29,43 t.ha ${ }^{-1}$ para a biomassa do fuste, 4,34 tha-1 para folhas e 32,24 t.ha ${ }^{-1}$ para a biomassa total. Cyathea corcovadensis obteve média de 2,75 t.ha-1 para fuste, 0.47 t.ha ${ }^{-1}$ para folhas e 3,53 t.ha-1 para a biomassa total.

Tabela 5. Estatística descritiva da biomassa por hectare $\left(\mathrm{t}_{\mathrm{h}} \mathrm{a}^{-1}\right)$ das espécies Dicksonia sellowiana e Cyathea corcovadensis em um fragmento de Floresta Ombrófila Mista

\begin{tabular}{ccccccc}
\hline \multirow{2}{*}{ Estatística } & \multicolumn{3}{c}{ Dicksonia sellowiana } & \multicolumn{3}{c}{ Cyathea corcovadensis } \\
\cline { 2 - 7 } & $\mathrm{BC}$ & $\mathrm{BF}$ & $\mathrm{BT}$ & $\mathrm{BC}$ & $\mathrm{BF}$ & $\mathrm{BT}$ \\
\hline Média & 29,43 & 4,34 & 32,24 & 2,75 & 0,47 & 3,53 \\
Desvio padrão & 8,36 & 1,22 & 11,94 & 1,79 & 0,26 & 2,08 \\
Mínimo & 15,28 & 2,29 & 1,87 & 0,76 & 0,13 & 0,95 \\
Máximo & 50,36 & 7,26 & 57,58 & 7,38 & 1,06 & 8,57 \\
\hline
\end{tabular}

Em que: $\mathrm{BC}=$ biomassa do fuste; $\mathrm{BF}=$ biomassa das folhas; e $\mathrm{BT}=$ biomassa total.

A distribuição da biomassa por hectare entre as duas espécies seguiu padrão semelhante. 0 componente fuste apresentou maior fração de biomassa com valores entre 85 e $87 \%$. O componente folha contou com valores entre 13 e 15\% da biomassa. Vieira et al. (2012), ao estudarem a biomassa em um povoamento de Eucalyptus urograndis, obtiveram biomassa acima do solo de $18,5 \mathrm{Mg}^{-\mathrm{ha}^{-1}}$, sendo o fuste a fração que apresentou maior biomassa (37,0\% do total), seguido de galhos $(34,2 \%)$, folhas $(21,3 \%)$ e casca $(7,6 \%)$.

Em um estudo conduzido por Schumacher et al. (2002) com a espécie exótica Pinus taeda L., o acúmulo da biomassa num povoamento aos 20 anos de idade foi de aproximadamente 203, 11, 48 e 8 t.ha $^{-1}$, para as frações madeira, casca, galhos e acículas respectivamente, totalizando 270 t.ha $^{-1}$. $\mathrm{Na}$ Floresta Ombrófila Mista Montana, Caldeira (2003a) encontrou um total de 280,73 t.ha-1 de biomassa, sendo que, da biomassa acima do solo, $75 \%$ foi representado por árvores com DAP maior do que 10 $\mathrm{cm}$ e $7,8 \%$ pelas árvores abaixo de $10 \mathrm{~cm}$, além de $14,4 \%$ representados pelas raízes e 2,8\% da biomassa acumulada na serapilheira. Os resultados de vários estudos mostram que o conteúdo de biomassa não segue um padrão, podendo ser variável de acordo com as características de cada espécie. 


\section{Seleção das equações para estimativa da biomassa dos componentes}

As estatísticas descritivas das variáveis independentes utilizadas nos ajustes das equações estão descritas na Tabela 6.

Tabela 6. Estatística descritiva para as variáveis diâmetro da base e altura total das espécies Dicksonia sellowiana e Cyathea corcovadensis em um fragmento de Floresta Ombrófila Mista

\begin{tabular}{ccccc}
\hline \multirow{2}{*}{ Estatística } & \multicolumn{2}{c}{ Dicksonia sellowiana } & \multicolumn{2}{c}{ Cyathea corcovadensis } \\
\cline { 2 - 5 } & $\begin{array}{c}\text { Diâmetro na } \\
\text { base }(\mathrm{cm})\end{array}$ & $\begin{array}{c}\text { Altura total } \\
(\mathrm{m})\end{array}$ & $\begin{array}{c}\text { Diâmetro na } \\
\text { base }(\mathrm{cm})\end{array}$ & $\begin{array}{c}\text { Altura total } \\
(\mathrm{m})\end{array}$ \\
\hline Média & 28,87 & 3,01 & 20,55 & 2,42 \\
Desvio padrão & 7,70 & 0,65 & 5,77 & 0,55 \\
Mínimo & 11,30 & 1,30 & 15,20 & 1,77 \\
Máximo & 49,50 & 5,56 & 38,60 & 4,48 \\
\hline
\end{tabular}

As seis equações ajustadas apresentaram erro-padrão da estimativa variando de $38,81 \%$ a $130 \%$ e coeficiente de determinação ajustado variando de 0,589 a 0,824 . O menor erro padrão e o maior coeficiente de determinação ajustado foram obtidos pela equação 6 (Tabela 7), que teve como variável independente o diâmetro da base $(d)$, a altura total $(h)$ e a variável combinada ( $\left.d^{2} h\right)$. Essa equação também apresentou uma adequada distribuição dos resíduos (Figura 3).

Tabela 7. Resultado do ajuste de equações para o componente fuste das espécies Dicksonia sellowiana e Cyathea corcovadensis em um fragmento de Floresta Ombrófila Mista

\begin{tabular}{lccc}
\hline & Equação & $\mathbf{R}^{\mathbf{2}}$ & Syx\% \\
\hline 1$)$ & $\mathrm{w}=-13,2336+1,10901\left(\mathrm{~d}^{2} \mathrm{~h}\right)+\mathrm{ei}$ & 0,713 & 44,81 \\
$2)$ & $\mathrm{w}=0,583162+0,020061\left(\mathrm{~d}^{2}\right)+\mathrm{ei}$ & 0,589 & 53,68 \\
$3)$ & $\mathrm{w}=3,926295+0,004652(\mathrm{~d})+\mathrm{ei}$ & 0,598 & 53,08 \\
$4)$ & $\operatorname{In}(\mathrm{w})=-2,97826+1,334887 \operatorname{In}(\mathrm{d})+1,135274+\mathrm{ei}$ & 0,822 & 43,68 \\
$5)$ & $\operatorname{In}(\mathrm{w})=-3,51051+0,803879 \operatorname{In}\left(\mathrm{d}^{2} \mathrm{~h}\right)+\mathrm{ei}$ & 0,817 & 130,00 \\
$6)$ & $\operatorname{In}(\mathrm{w})=-3,88913+1,604493 \operatorname{In}(\mathrm{d})+1,361082 \operatorname{In}(\mathrm{h})+-0,00007\left(\mathrm{~d}^{2} \mathrm{~h}\right)+\mathrm{ei}$ & 0,824 & 38,81 \\
\hline
\end{tabular}

Para a folhagem, as equações ajustadas não apresentaram bons resultados, revelando baixo coeficiente de determinação ajustado e alto erro padrão da estimativa. Para o coeficiente de determinação, foram encontrados valores entre 0,495 e 0,595. O erro padrão da estimativa variou entre 50 e $64 \%$ (Tabela 8). Miranda (2008), ao estudar a biomassa seca de folhas em áreas de restauração ambiental, encontrou valores para o coeficiente de determinação entre 0,3276 e 0,8198, respectivamente para espécies de crescimento médio e lento.

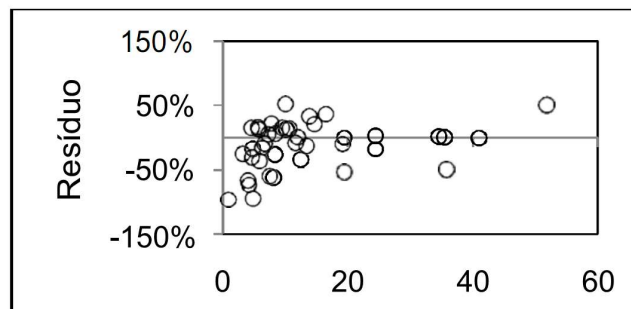

(4) Biomassa do fuste observada $(\mathrm{kg})$

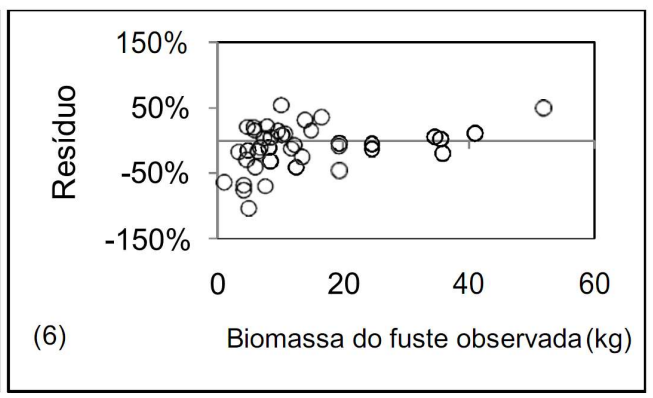

Figura 3. Distribuição de resíduos das equações selecionadas para biomassa do fuste das espécies Dicksonia sellowiana e Cyathea corcovadensis em fragmento de Floresta Ombrófila Mista.

Além dos baixos índices de ajustes, no geral, as equações geraram tendências, assim os melhores modelos foram escolhidos pela análise gráfica dos resíduos (Figura 4). A melhor equação ajustada para a estimativa da biomassa das folhas foi a equação 4, apesar de apresentar estatísticas imprecisas. 
Tabela 8. Resultado do ajuste de equações para o componente folhas das espécies Dicksonia sellowiana e Cyathea corcovadensis em um fragmento de Floresta Ombrófila Mista

\begin{tabular}{cccc}
\hline & Equação & $\mathbf{R}^{\mathbf{2}}$ & $\mathbf{S y x} \%$ \\
\hline 1$)$ & $\mathrm{w}=0,83184+0,000654\left(\mathrm{~d}^{2} \mathrm{~h}\right)+\mathrm{ei}$ & 0,595 & 50,84 \\
$2)$ & $\mathrm{w}=0,289811+0,020061\left(\mathrm{~d}^{2}\right)+\mathrm{ei}$ & 0,531 & 54,70 \\
$3)$ & $\mathrm{w}=-1,73481+0,162219(\mathrm{~d})+\mathrm{ei}$ & 0,541 & 54,09 \\
$4)$ & $\operatorname{In}(\mathrm{w})=-4,67868+1,410236 \operatorname{In}(\mathrm{d})+0,735023+\mathrm{ei}$ & 0,508 & 51,00 \\
$5)$ & $\operatorname{In}(\mathrm{w})=-4,71236+0,713787 \operatorname{In}\left(\mathrm{d}^{2} \mathrm{~h}\right)+\mathrm{ei}$ & 0,521 & 50,00 \\
$6)$ & $\operatorname{In}(\mathrm{w})=-4,36250+1,316652 \operatorname{In}(\mathrm{d})+0,656641 \operatorname{In}(\mathrm{h})+-0,000026\left(\mathrm{~d}^{2} \mathrm{~h}\right)+\mathrm{ei}$ & 0,495 & 64,00 \\
\hline
\end{tabular}

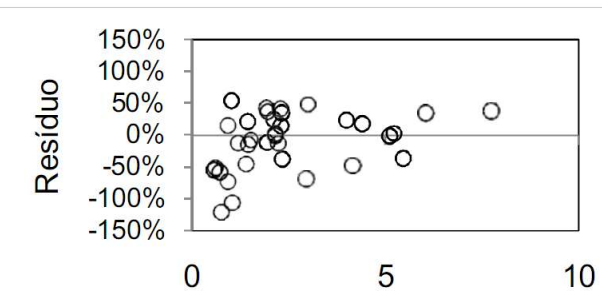

(4) Biomassa de folhas estimada $(\mathrm{kg})$

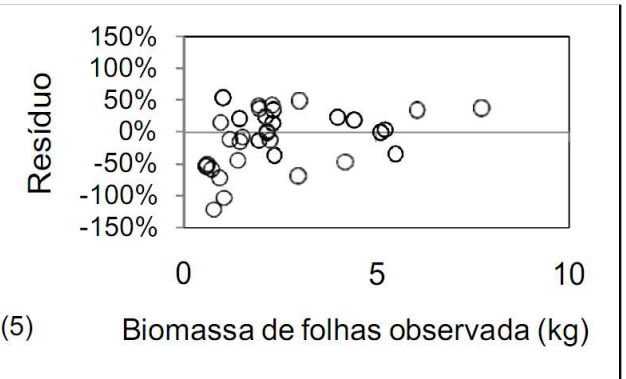

Figura 4. Distribuição de resíduos das equações selecionada para biomassa das folhas das espécies Dicksonia sellowiana e Cyathea corcovadensis em um fragmento de Floresta Ombrófila Mista.

Os melhores modelos para estimativa da biomassa total foram os modelos 4,5 e 6 . Os valores de erro-padrão da estimativa variaram entre 38 e 50,91\% e coeficiente de determinação ajustado entre 0,609 e 0,827 (Tabela 9). O modelo para estimativa da biomassa total foi escolhido em função da análise gráfica dos resíduos, sendo assim, a equação 6 apresentou resultados mais satisfatórios (Figura 5).

Tabela 9. Resultado do ajuste de equações para a biomassa total das espécies Dicksonia sellowiana e Cyathea corcovadensis em um fragmento de Floresta Ombrófila Mista

\begin{tabular}{cccc}
\hline & Equação & $\mathbf{R}^{\mathbf{2}}$ & $\mathbf{S y x} \%$ \\
\hline 1$)$ & $\mathrm{w}=-14,9688+1,271244\left(\mathrm{~d}^{2} \mathrm{~h}\right)+\mathrm{ei}$ & 0,730 & 50,27 \\
$2)$ & $\mathrm{w}=0,872696+0,022991\left(\mathrm{~d}^{2}\right)+\mathrm{ei}$ & 0,609 & 50,91 \\
$3)$ & $\mathrm{w}=4,757943+0,00506(\mathrm{~d})+\mathrm{ei}$ & 0,618 & 42,29 \\
$4)$ & $\operatorname{In}(\mathrm{w})=-2,65717+1,310227 \operatorname{In}(\mathrm{d})+1,05658+\mathrm{ei}$ & 0,827 & 40,00 \\
$5)$ & $\operatorname{In}(\mathrm{w})=-3,11391+0,772194 \operatorname{In}\left(\mathrm{d}^{2} \mathrm{~h}\right)+\mathrm{ei}$ & 0,824 & 41,00 \\
$6)$ & $\operatorname{In}(\mathrm{w})=-3,17038+1,462132 \operatorname{In}(\mathrm{d})+1,183807 \operatorname{In}(\mathrm{h})+-0,00004\left(\mathrm{~d}^{2} \mathrm{~h}\right)+\mathrm{ei}$ & 0,824 & 38,00 \\
\hline
\end{tabular}

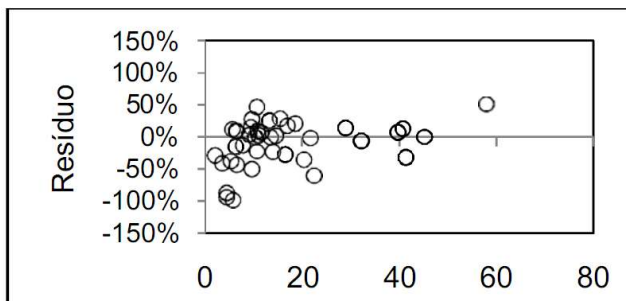

(5)

Biomassa total observada $(\mathrm{kg})$

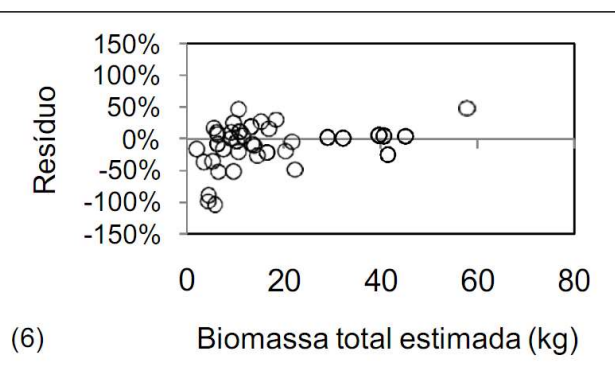

Figura 5. Distribuição de resíduos das equações selecionadas para biomassa total das espécies Dicksonia sellowiana e Cyathea corcovadensis em um fragmento de Floresta Ombrófila Mista.

\section{Teores e estoque de carbono}

Os resultados dos teores de carbono dos 40 indivíduos amostrados estão apresentados em 
forma de análise descritiva na Tabela 10. A média para o componente fuste foi de 40,53\% com valores mínimos e máximos de 38,44 e 42,13\% respectivamente. Já o componente folha obteve média de $38,64 \%$ do teor de carbono, com porcentagem mínima de $34,07 \%$ e máxima de $42,01 \%$. Considerando todos os componentes, o valor médio ponderado dos teores de carbono foi de $40,28 \%$.

Tabela 10. Teores de carbono das espécies Dicksonia sellowiana e Cyathea corcovadensis, situadas em um fragmento de Floresta Ombrófila Mista

\begin{tabular}{ccc}
\hline Estatística & Fuste & Folhas \\
\hline Média & 40,53 & 38,64 \\
Desvio padrão & 0,81 & 1,59 \\
Mínimo & 38,44 & 34,07 \\
Máximo & 42,13 & 42,01 \\
\hline
\end{tabular}

Para avaliar as possíveis diferenças entre os teores de carbono dos diferentes componentes avaliados e entre as diferentes espécies, realizou-se a Análise de Variância (ANOVA). Os resultados estão representados na Tabela 11 .

Tabela 11. Análise de variância do teor de carbono das espécies Dicksonia sellowiana e Cyathea corcovadensis em um fragmento de Floresta Ombrófila Mista

\begin{tabular}{ccc}
\hline Fonte de variação & GL & QM \\
\hline Espécie & 1 & $270927,68^{* *}$ \\
Componente & 2 & $256433,09^{* *}$ \\
Espécie x Componente & 2 & $22890,32^{\text {ns }}$
\end{tabular}

Em que: ${ }^{* *}=$ significativo a $1 \%$ de probabilidade; e ns = não significativo a $1 \%$ de probabilidade.

O Teste de Tukey revelou que os componentes fuste e total possuem valor mais elevado comparando ao componente folha. Machado et al. (2006), analisando o carbono fixado em Mimosa scabrella, constataram a existência de diferença estatística entre as folhas e os demais componentes. Em relação às espécies, o teste também apresentou diferenças significativas nos teores de carbono (Tabela 12). Tais diferenças podem ser explicadas pelas características de cada espécie, como, por exemplo, sua adaptação às condições edafoclimáticas. Apesar de inseridas no mesmo ambiente, cada espécie se comporta de forma diferenciada, o que pode influenciar no crescimento e na incorporação de carbono na biomassa das plantas.

Tabela 12. Teste de Tukey do teor de carbono das espécies Dicksonia sellowiana e Cyathea corcovadensis em um fragmento de Floresta Ombrófila Mista

\begin{tabular}{ccc}
\hline Componente & Média & Grupo \\
\hline Fuste & 40,53 & $\mathrm{a}$ \\
Total & 40,28 & $\mathrm{a}$ \\
Folhas & 38,64 & $\mathrm{~b}$ \\
\hline Espécie & Média & Grupo \\
\hline Dicksonia sellowiana & 40,42 & $\mathrm{a}$ \\
Cyathea corcovadensis & 39,21 & $\mathrm{~b}$ \\
\hline
\end{tabular}

Em que: letras distintas na coluna indica que os fatores diferem entre si a $1 \%$ de probabilidade conforme o teste de Tukey.

Watzlawick et al. (2011), ao estudarem a variação dos teores de carbono em espécies arbóreas da Floresta Ombrófila Mista, observaram heterogeneidade nos teores de carbono entre os componentes, encontrando os seguintes valores: folhagem igual a 42,30\%, galho morto de 41,24\%, madeira do fuste equivalente a 41,76\%, galho vivo de 40,61 e casca igual a37,97\%. Weber et al. (2006), analisando os teores de carbono em seis espécies naturais da Floresta Ombrófila Mista, constataram maior teor de carbono na porção folhas (44,2\%), ao passo que Machado et al. (2006), avaliando os teores de carbono da espécie Mimosa scabrella Benth, obtiveram média dos teores de carbono de $45,46 \%$ para folhas e de 43,68 para fuste.

Saidelles et al. (2008), avaliando os teores de carbono em Acacia mearnsii De Wild. no Rio Grande do Sul, constataram diferença significativa nos teores das folhas, sendo que os demais componentes não apresentaram diferença. Os teores de carbono encontrados neste trabalho, 
comparativamente com outros trabalhos citados, comprovam que dificilmente existem teores que ultrapassam valores de $50 \%$ e que, assim como nas espécies arbóreas nativas, os teores de carbono encontrados em samambaias arborescentes encontram-se em proximidade.

As estatísticas descritivas dos valores de estoque individual de carbono para as duas espécies estão apresentadas na Tabela 13. Dicksonia sellowiana obteve estoque médio de carbono individual de $6,89 \mathrm{~kg}$ para fuste, $0,97 \mathrm{~kg}$ para folhas e o total de $7,89 \mathrm{~kg}$. Cyathea corcovadensis apresentou estoque médio de carbono individual de $3,34 \mathrm{~kg}$ para fuste, $0,50 \mathrm{~kg}$ para folhas e um total de $3,91 \mathrm{~kg}$.

Tabela 13. Estoque individual de carbono das Dicksonia sellowiana e Cyathea corcovadensis em um fragmento de Floresta Ombrófila Mista

\begin{tabular}{ccccccccc}
\hline & \multicolumn{6}{c}{ Carbono total individual (kg) } \\
\cline { 2 - 9 } Componente & \multicolumn{4}{c}{ Dicksonia sellowiana } & \multicolumn{4}{c}{ Cyathea corcovadensis } \\
\cline { 2 - 9 } & Média & Erro padrão & Mínimo & Máximo & Média & Erro Padrão & Mínimo & Máximo \\
\hline Fuste & 6,89 & 0,24 & 0,68 & 16,58 & 3,34 & 0,38 & 1,45 & 8,08 \\
Folha & 0,97 & 0,03 & 0,15 & 2,56 & 0,50 & 0,05 & 0,27 & 1,26 \\
Total & 7,89 & 0,28 & 0,92 & 19,94 & 3,91 & 0,42 & 1,83 & 9,38 \\
\hline
\end{tabular}

A distribuição do estoque individual de carbono nos compartimentos seguiu padrão semelhante ao da biomassa seca: $88 \%$ no fuste e $12 \%$ nas folhas para Dicksonia sellowiana e $87 \%$ no fuste e $13 \%$ nas folhas para Cyathea corcovadensis. A Tabela 14 apresenta os estoques de biomassa e carbono $\left(\right.$ t.ha $\left.^{-1}\right)$ para as espécies avaliadas. A capacidade de fixação de carbono de Dicksonia sellowiana atingiu 11,92 t.ha-1, Cyathea corcovadensis chegou a 1,11 t.ha-1 e ambas totalizaram 13,03 t.ha-1

Tabela 14. Estoque de biomassa e carbono (t.ha $\left.{ }^{-1}\right)$ das espécies Dicksonia sellowiana e Cyathea corcovadensis em um fragmento de Floresta Ombrófila Mista

\begin{tabular}{ccccc}
\hline \multirow{2}{*}{ Componente } & \multicolumn{2}{c}{ Dicksonia sellowiana } & \multicolumn{2}{c}{ Cyathea corcovadensis } \\
\cline { 2 - 5 } & Biomassa & Carbono & Biomassa & Carbono \\
\cline { 2 - 5 } & \multicolumn{3}{c}{$\left(\right.$ t.ha $\left.^{-1}\right)$} \\
Fuste & 29,43 & 11,92 & 2,75 & 1,11 \\
Folhas & 4,34 & 1,67 & 0,47 & 0,18 \\
Total & 32,24 & 12,98 & 3,53 & 1,42 \\
\hline
\end{tabular}

Em um estudo sobre reflorestamentos de matas ciliares no sudoeste paulista, com idades entre 1 e 28 anos em diferentes tipos de solos, Melo e Durigan (2006) encontraram estoques de carbono na parte aérea das árvores variando entre 0,6 e 149,0 t.ha-1. Em plantações de Acacia mearnsii com 6 anos de idade, Caldeira et al. (2003b) encontraram os seguintes valores para o estoque de carbono fixado: folhas de 3,43 t.ha- $^{-1}$, galhos mortos iguais a 1,38 t.ha-1, galhos vivos equivalente a 6,29 t.ha- $^{-1}$, casca de 3,01 t.ha-1, fuste igual a 36,63 t.ha-1 e raízes de 5,02 t.ha-1.

Mognon (2011), ao avaliar a dinâmica do estoque de carbono em diferentes grupos da Floresta Ombrófila Mista Montana, observou que o grupo da Araucaria angustifolia manteve maior

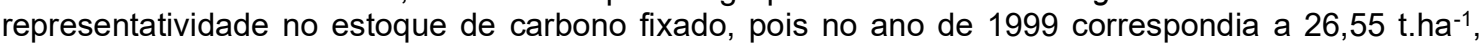
passando para 28,82 t.ha-1. Já no grupo das Canelas, a espécie Ocotea porosa foi a mais representativa, sendo que em 1999 correspondia a 21,71 t. ha-1, finalizando com 22,55 t.ha-1. A literatura mostra que o estoque de carbono na biomassa varia em função da idade.

\section{Dióxido de carbono equivalente}

$\mathrm{Na}$ estimativa do $\mathrm{CO}_{2}$ equivalente, seguiu-se a mesma tendência dos valores apresentados para a biomassa do fragmento. Dicksonia sellowiana apresentou sequestro de $\mathrm{CO}_{2}$ equivalente a 47,63 t.ha ${ }^{-1}$ distribuída nos seguintes percentuais: $88 \%$ para fuste e $12 \%$ para folhas. Cyathea corcovadensis obteve média de 5,21 t.ha-1, com proporções de $86 \%$ para fuste e 14\% para folhas (Tabela 15).

Os valores de $\mathrm{CO} 2$ equivalente podem ser usados como referência para o estabelecimento de projetos REDD+, mecanismo que permite a remuneração daqueles que mantém suas florestas em pé, conferindo um valor econômico à quantidade de carbono que a área preservada acumula em suas partes vegetais. Nota-se a importância desse estudo para Floresta Ombrófila Mista, que se encontra com poucos fragmentos preservados, os quais poderiam ser passíveis de estabelecimento dos projetos de carbono. 
Tabela 15. Estoque de carbono equivalente $\left(\mathrm{CO}_{2} \mathrm{Eq}\right.$. $)$ para as espécies Dicksonia sellowiana e Cyathea corcovadensis, situadas em um fragmento de Floresta Ombrófila Mista

\begin{tabular}{ccc}
\hline Componente & Dicksonia sellowiana & Cyathea corcovadensis \\
\hline Fuste & $43,74\left(\right.$ t.ha $\left.^{-1}\right)$ & $4,07\left(\right.$ t.ha $\left.^{-1}\right)$ \\
Folhas & $6,12\left(\right.$ t.ha $\left.^{-1}\right)$ & $0,66\left(\right.$ t.ha $\left.^{-1}\right)$ \\
Total & $47,63\left(\right.$ t.ha $\left.^{-1}\right)$ & $5,21\left(\right.$ t.ha $\left.^{-1}\right)$ \\
\hline
\end{tabular}

\section{CONCLUSÕES}

A biomassa encontrada nos xaxins do fragmento estudado apresentou total de $35,77 \mathrm{t}^{-\mathrm{ha}^{-1}}$, em que a Dicksonia sellowiana obteve estoque médio de 29,43 t.ha $^{-1}$ para o componente fuste, 4,34 t.ha ${ }^{-1}$ para folhas e 32,24 t.ha $^{-1}$ para a biomassa total. Ao passo que Cyathea corcovadensis obteve média de 2,75 t.ha-1 para fuste, 0.47 t.ha $^{-1}$ para folhas e 3,53 t.ha-1 para a biomassa total.

O teor médio de carbono foi de $40,53 \%$ para o fuste e de $38,64 \%$ para as folhas, enquanto o valor médio ponderado dos teores de carbono foi de $40,28 \%$ ao considerar todos os componentes. Ademais, o estoque de carbono para as duas espécies totalizou 13,03 t.ha-1, sendo 11,92 t.ha-1 para Dicksonia sellowiana e 1,11 tha-1 para Cyathea corcovadensis.

\section{REFERÊNCIAS}

ABNT - Associação Brasileira de Normas Técnicas. NBR 11941: Determinação da densidade básica. Rio de Janeiro, 2003.

CALDEIRA, M. V. W. Determinação de biomassa e nutrientes em uma Floresta Ombrófila Mista Montana em General Carneiro, Paraná. 2003a. Tese (Doutorado em Engenharia Florestal) Universidade Federal do Paraná, Curitiba.

CALDEIRA, M. V. W. Determinação de carbono em povoamentos de Acacia mearnsii de WILD. plantados no Rio Grande do Sul. Acadêmica, v. 1, n. 2, p. 47-54, 2003b.

CAVALLET, L. E.; PAULA, V. P. Estimativa de sequestro de carbono da biomassa aérea como indicador de sustentabilidade em decorrência da adequação da área de preservação permanente da sub-bacia do Rio Pequeno (Antônia - PR). Curitiba: UFPR, 2007.

DOBNER, M.; VAGAES, T. C.; HIGA, A. R. Aproveitamento do germoplasma de Cryptomeria japonica da Estação Experimental de Rio Negro, PR, visando a produção de sementes. Floresta, v. 43, n. 3, p. 363-372, 2013.

IBGE - Instituto Brasileiro de Geografia e Estatística. Manual técnico da vegetação brasileira. Rio de Janeiro, 2. ed. 2012.

IPCC - Intergovernmental Panel on Climate Change. Climate change 2007. Physical Science Basis: Synthesis report. contribution of working group I, II, and III to the third assessment report of the IPCC. Cambridge: Cambridge University Press, 2007.

HIRAI, R. Y.; PRADO, J. Criptógamos do Parque Estadual das Fontes do Ipiranga, São Paulo, SP, Brasil. Pteridophyta: 3. Cyatheaceae. Hoehnea, v. 41, n. 2, p. 173-180, 2014.

LEHN, C. R.; SCHMITT, J. L.; WINDISCH, P. G. Aspectos do desenvolvimento vegetativo de Rumohra adiantiformis (Forst.) Ching (Pteridophyta, Dryopteridaceae), em condições naturais. Revista de Estudos / Centro Universitário Feevale, v. 25, n. 2, p. 21-28, 2002.

MACHADO, S. do A.; URBANO, E.; JARSCHEL, B.; TEO, S. J.; FIGURA, M. A.; SILVA, L.C. R. da. Relações quantitativas entre variáveis dendrométricas e teores de carbono para Mimosa scabrella Bentham da região metropolitana de Curitiba. Boletim de Pesquisa Florestal, n. 52, p. 37-60, 2006.

MANTOVANI, M. Caracterização de populações naturais de xaxim (Dicksonia sellowiana (Presl.) Hooker), em diferentes condições edafo-climáticas no Estado de Santa Catarina. 2004. 
Dissertação (Mestrado em Recursos Genéticos Vegetais) - Universidade Federal de Santa Catarina, Florianópolis.

MELO, A. C. G.; DURIGAN, G. Fixação de carbono em reflorestamentos de matas ciliares no Vale do Paranapanema, SP, Brasil. Scientia Forestalis, n. 71, p. 149-154, 2006.

MIRANDA, D. L. C. de; SANQUETTA, C. R.; COSTA, L. G. da S.; CORTE, A. P. Biomassa e Carbono em Euterpe oleracea Mart., na Ilha do Marajó - PA. Floresta e Ambiente, v. 19, n. 3, p. 336-343, 2012.

MIRANDA, D. L. C. Modelos matemáticos de estoque de biomassa e carbono em áreas de restauração florestal no sudoeste paulista. 2008. Dissertação de Mestrado (Mestrado em Engenharia Florestal) - Universidade Federal do Paraná, Curitiba.

MOGNON, F. Dinâmica do estoque de carbono como serviço ambiental prestado por um fragmento de floresta Ombrófila Mista Montana localizada no sul do estado do Paraná. 2011. Dissertação (Mestrado em Engenharia Florestal) - Universidade Federal do Paraná, Curitiba.

NEUMANN, M. K. Monitoramento do Crescimento e da Fenologia de Cyathea corcovadensis (Raddi) Domin (Cyatheaceae), em Remanescente de Floresta Atlântica, RS, Brasil. 2010. Dissertação (Mestrado em Qualidade Ambiental) - Centro Universitário Feevale, Novo Hamburgo.

OSHIRO, S. R. Processo de Medição de Carbono de Biomassa Arbóreo não- agressivo ao Ecossistema - Estudo de Caso: Mimosa scabrella Bentham. 2010. Dissertação (Mestrado em Engenharia Florestal) - Universidade Federal do Paraná, Curitiba.

PELLIZZARO, L. Biomassa e estoque de carbono na parte aérea de espécies arbóreas nativas no município de Chapecó, Santa Catarina. 2009. Dissertação (Mestrado em Ciências Ambientais) Universidade Comunitária da Região de Chapecó, Santa Catarina.

PEREIRA, A. B. Introdução ao estudo das pteridófitas. Canoas: Ed. ULBRA, 2 ed. 2003.

SAIDELLES, F. L. F.; CALDEIRA, M. V. W.; SCHUMACHER, M. V.; BALBINOT, R. Uso de equações para estimar carbono orgânico em plantações de Acacia mearnsii de Wild. no Rio Grande do Sul Brasil. Árvore, v. 33, n. 5, p. 907-915, 2009.

SANQUETTA, C. R. Métodos de determinação de biomassa florestal. In: SANQUETTA, C. R. et al.(Eds.). As florestas e o carbono. Curitiba, 2002.

SANTOS, W. C. A influência de fatores edáficos no crescimento e produção de 12 diferentes procedências de Araucaria angustifolia (Bert.) O. Kuntze. 2006. Dissertação (Mestrado em Engenharia Florestal) - Universidade Federal do Paraná, Curitiba.

SCHNEIDER, P. R.; SCHNEIDER, P. S. P.; SOUZA, C. A. M. Análise de regressão aplicada à Engenharia Florestal. Santa Maria: FACOS-UFSM, 2. ed. 2009.

SEHNEM, A. Ciateáceas. In: REITZ, P. R. Flora Ilustrada Catarinense. Itajaí-SC: Herbário Barbosa Rodrigues, 1978.

SEMA. Espécies da flora ameaçadas de extinção do Rio Grande do Sul. Disponível em: <http://www.icmbio.gov.br/cepsul/images/stories/legislacao/Decretos/2002/dec_rs_42099_2002_espe cies_floranativa_ameacadasdeextincao_rs.pdf> Acesso em: 15/07/2014.

SILVEIRA, P. Métodos indiretos de estimativa do conteúdo de biomassa e do estoque de carbono em um fragmento de Floresta Ombrófila Densa. 2008. Tese (Doutorado em Engenharia Florestal) Universidade Federal do Paraná, Curitiba.

SCHUMACHER, M. V.; WITSCHORECK, R.; CALDEIRA, M. V. W.; WATZLAWICK, L. F. Estoque de carbono em florestas de Pinus taeda L. e Acacia mearnsii De Wild. plantadas no Estado do Rio Grande 
do Sul. As florestas e o Carbono. Curitiba, 2002.

URBANO, E. Estimativa da biomassa aérea e do peso de carbono fixado em árvores de bracatingas nativas da região metropolitana de Curitiba. 2007. Dissertação (Mestrado em Engenharia Florestal) - Universidade Federal do Paraná, Curitiba.

WATZLAWICK, L. F.; BALBINOT, R.; SANQUETTA, C. R.; CALDEIRA, M. V. W. Teores de carbono em espécies da Floresta Ombrófila Mista. In: SANQUETTA, C. R.; BALBINOT, R.; ZILIOTO, M. A. Fixação de carbono: atualidades, projetos e pesquisas. Curitiba, p. 65-80, 2004.

WATZLAWICK, L. F.; EBLING, Â. A.; RODRIGUES, A. L.; VERES, Q. J. I.; LIMA, A. M. de. Variação nos teores de carbono orgânico em espécies arbóreas da Floresta Ombrófila Mista. Floresta e Ambiente, v. 18, n. 3, p. 248-258, 2011.

WEBER, K. S.; BALBINOT, R.; WATZLAWICK, L. F.; SANQUETTA, C. R. Teores de carbono orgânico de seis espécies naturais do ecossistema da Floresta Ombrófila Mista. Ambiência, v. 2, n. 2, p. 167$177,2006$. 